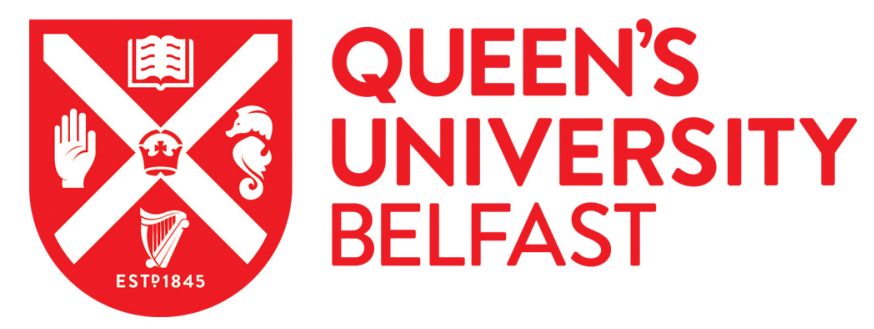

\title{
Living a fairy tale: the educational experiences of transgender and gender non-conforming youth in Northern Ireland
}

McBride, R-S., \& Schubotz, D. (2017). Living a fairy tale: the educational experiences of transgender and gender non-conforming youth in Northern Ireland. Childcare in Practice, 1-13.

https://doi.org/10.1080/13575279.2017.1299112

\section{Published in:}

Childcare in Practice

\section{Document Version:}

Peer reviewed version

\section{Queen's University Belfast - Research Portal:}

Link to publication record in Queen's University Belfast Research Portal

\section{Publisher rights}

(c) 2017 The Child Care in Practice Group.

This work is made available online in accordance with the publisher's policies. Please refer to any applicable terms of use of the publisher.

\section{General rights}

Copyright for the publications made accessible via the Queen's University Belfast Research Portal is retained by the author(s) and / or other copyright owners and it is a condition of accessing these publications that users recognise and abide by the legal requirements associated with these rights.

Take down policy

The Research Portal is Queen's institutional repository that provides access to Queen's research output. Every effort has been made to ensure that content in the Research Portal does not infringe any person's rights, or applicable UK laws. If you discover content in the Research Portal that you believe breaches copyright or violates any law, please contact openaccess@qub.ac.uk. 
Living a fairy tale: The educational experiences of gender non-conforming youth in Northern Ireland

\begin{abstract}
This paper investigates the educational experiences of transgender and gender nonconforming (TGNC) youth living in Northern Ireland through a mixed-methods research design and analytical framework of heteronormativity. It draws on large scale survey data, which, for the first time in Northern Ireland (NI), captured the experiences of 16-year olds who identify as TGNC. This provides a baseline of the demographics of TGNC youth living in NI and the levels of homophobic and transphobic abuse they experience in school. Survey data is triangulated with findings from five qualitative interviews that explore the subjective experiences of TGNC youth in educational environments. Interview data reveals how heteronormativity is embedded in educational policies and practices. This institutionalisation of heteronormativity was found to be linked to the influence of conservative Christian values, which inhibit open and positive dialogue about TGNC and non-heterosexual identities, in educational domains. We show how educational environments shaped by heteronormativity and conservative Christian values serve to undermine the self-determination and freedom of expression of TGNC youth. In conclusion, we offer practical examples of counterheteronormative interventions that will assist educators and schools in NI to develop empathetic practice and supportive environments that will erode the inequality and injustice TGNC youth experience in pedagogical institutions.
\end{abstract}

Keywords: Transgender, gender non-conformity, heteronormativity, counterheteronormativity, education, school, religion, Christianity 
"Watching fairy tales, I thought that some witch had cast a spell on me as a baby. That was what I thought when I was a kid that it was a sick joke and one day it would be cured. I really thought I was the only one in Northern Ireland.” Sarah

Transgender and gender non-conforming (TGNC) youth embody, self-identify and/or express their gender in a way that differs from their assigned birth gender. Research has shown that the lived experiences of TGNC youth are deeply impacted by heteronormativity. Heteronormativity is defined here as a dominant mode of social organisation based on: a) a foundational division of boys/men from girls/women; and, b) the institutionalisation of heterosexuality as natural and normal. Heteronormative societies promulgate a patriarchal gender hierarchy, which privileges boys/men who conform to a hegemonic notions of masculinity and femininity. In turn, it implicitly condones, and actively legitimises, forms of violence against people who do not conform to cultural gender norms, including those who identify as TGNC. Research has shown that heteronormativity within educational environments has a detrimental impact on the lives of TGNC youth. However, to date no academic research has been published into the educational experiences of TGNC youth living in Northern Ireland (NI).

In this article, we investigate the educational experiences of TGNC youth who live in NI through a mixed-methods design. We analyse data drawn from the 2014 Young Life and Times Survey (YLT) and five semi-structured interviews conducted with TGNC youth (aged 12-23). Analysis of YLT survey data suggests that despite diverse demographics, TGNC youth collectively experience high levels of homophobic and transphobic abuse in educational settings compared to other pupils. Analysis of interview data offers deeper insight into the different ways in which heteronormativity shape TGNC youth's educational experience. In particular, it reveals how conservative Christian values prevent open and positive dialogue regarding TGNC and non-heterosexual identities. We show how this 
discursive erasure has a profound impact on TGNC youth since it limits their capacity for self-determination and inhibits their freedom of expression. To conclude we highlight counter-heteronormative interventions that can aide educators and schools to benefit TGNC youth.

\section{Literature review}

Within heteronormative societies knowledge systems, social institutions and the political economy are founded on, and serve to re-produce, a binary heterosexual gender order, which divides humans into two genders (male and female) and assumes heterosexual relations to be healthy and normal (Ingraham, 1994; Moi, 2005). This basic gender division underpins patriarchal social relations, which endow boys/men with power and privilege over girls/women; and, affords advantages and opportunities to heterosexuals over nonheterosexuals. In heteronormative societies cisgenderism, which assumes a person born with a penis/vagina, will identify as a man/woman and will express themselves as masculine/feminine, is naturalised and normalised (see Ansara \& Hegarty, 2012). Consequently gender atypical behaviour is highly stigmatised - as abnormal, deviant and/or pathological - and may produce non-violent and violent reactions in others (Nielsen, Walden, \& Kunkel, 2000). Research has shown that young people who do not conform to the cultural expectations of their assigned birth gender and identify as TGNC are subjected to multiple forms of prejudice, discrimination and violence (Toomey, McGuire, \& Russell, 2012).

Since the mid-2000s there has been a relative explosion in research exploring the experiences of TGNC people in the US and UK. Researchers have invariably found the TGNC community to be marginalised and vulnerable to discrimination and victimisation (Lombardi, Wilchins, Esq., \& Malouf, 2002). Emphasis has been placed on the negative physical and mental health impacts of this discrimination and victimisation, which includes 
negative self-esteem and internalised transphobia (Barry \& Goodman, 2016; Burgess, 1999); self-harming (Roen, 2015); and, depression, substance abuse, forced sex, and attempted suicide (Clements-Nolle, Marx \& Katz, 2006). The victimisation of TGNC identified people is often compounded by a lack of safe environments, poor access to physical health services, inadequate resources to address mental health, and a lack of continuity of caregiving by families and communities (Grossman \& D'augelli, 2006). Specific research into the lives of TGNC youth remains sparse, however, the evidence that exist suggests educational environments are central to TGNC youth's lived experience.

Educational environments play an important gendering function and often reproduce gender stereotypes (see Connell, 1989). As such, schools can be hostile environments for those who transgress gender norms (Irwin, 2002). The structure (e.g. single-sex schools) and the ethos (e.g. religious affiliated schools) of educational establishments can serve to reinforce a binary gender, heteronormative order (Bantjes \& Nieuwoudt, 2014; Saltmarsh, 2007). School curriculums that negate adequate information about gender and sexual diversity limits pupils understanding of the biological and social factors involved in gender identity formation (Boskey, 2014). This can serve to discursively erase the existence of TGNC and non-heterosexual identities (Rofes, 2000) and impedes all pupils' awareness and understanding of their own gender and sexual identity (Sigall \& Pabst, 2005). Uniform and hair cut policies often enforce gender norms (Mitchell \& Howarth, 2009). The existence of bullying policies, and the strength with which they are enforced, meanwhile, communicates whether harassment of TGNC youth is acceptable or not (Linville, 2011). A lack of training often leaves educators unprepared to adequately meet the needs of, or act as allies for, TGNC youth (Case \& Meier, 2012). All of these different factors shape a particular school's milieu and, in turn, shapes how teachers and students interact with TGNC pupils. In school environments that are overtly heteronormative any gender atypical behaviour can result in 
homophobic and transphobic bullying (Linville, 2011). The risk of violence means many TGNC may 'choose' to self-regulate, conform to gender norms and forego their authentic gender identity while at school (see Nielsen et al., 2000).

Research findings from the US and the UK have thus highlighted some of the ways in which TGNC youth's educational experiences are inflected with heteronormative expectations and practices that expose them to multiple forms of violence: discursive, psychological and physical (Yep, 2003). If harmful heteronormative practices are to be challenged at a local level it is essential to analyse how heteronormative educational practices manifest in particular historical and regional settings (see Ingraham, 1994). Furthermore, within a given context it is important to consider how TGNC youths' gender identity intersects with other aspects of their identity, such as their sexuality, ethnicity, skin colour, class, disability and religion (Yep, 2002). Critical analysis of heteronormativity in educational settings thus requires attentiveness to contextual specificities and matters of intersectionality.

To date little research has been conducted into the experiences of NI's TGNC community. The few policy reports that have been published (McBride \& Hansson, 2010; McBride, 2011, 2013) reveal TGNC youth living in NI share similar experiences as those described above: high levels of prejudice, discrimination and violence in private and public domains, which results in negative health outcomes. However, to date there has been no attempt to link the experiences of TGNC youth living in NI to the particularities of NI's historical trajectory, which has been dominated by conservative Christian values since its inception.

The conservative Christian moral order that is said to pervade NI (Inglis, 1987; Livingstone, Keane, \& Boal, 1998; Conrad, 1999; Mitchell, 2006) has been found to negatively impact public and political attitudes to lesbian, gay and bisexual (LGB) and 
TGNC rights (Hayes, 1995; Hayes \& Nagle, 2015; Kitchin \& Lysaght, 2004). Conservative Christianity also has a strong influence over the education system, since schools receive government funding on the basis of having a Christian-based ethos and curriculum (DE, 2015). This influence has, in the past, led to a delay in the introduction of compulsory sex education in NI's schools compared to other parts of the UK. Today, sex education is often taught with explicit religious overtones whilst religious and sexual education is still taught in ways that reaffirm heteronormativity (Rolston, Schubotz, \& Simpson, 2005). In this article, we examine the subjective experiences of TGNC youth living in NI as they relate to these structural conditions.

\section{Methods}

Researchers have noted that there is an urgent need for specific data about TGNC youth (Rachlin, 2009). This need is impeded, however, by the multiple challenges in securing the participation of TGNC youth in research projects, which has resulted in their perspectives and experiences being excluded from studies on gender and sexual minorities (Elze, 2009). There are attitudinal and methodological reasons for this. Due to the high level of discrimination and victimisation experienced by most, if not all, TGNC people, many are disinclined to engage with qualitative researchers due to the potential for their anonymity and confidentiality to be compromised. Meanwhile, the fact that the TGNC community has been a largely 'invisible' population until recently has also resulted in their exclusion from anonymised population survey research. Conventionally the TGNC community has been included as ' $\mathrm{T}$ ' in LGBT studies, but the comparatively small number of TGNC respondents meant that their views and experiences were rarely captured sufficiently. It is only recently, as awareness of the TGNC community has increased and TGNC people become more willing to self-identify, that large-scale surveys, such as the FRA study (European Union Agency for Fundamental Rights, 2014), have begun to capture demographic data on gender identities that 
fall outside of the male-female binary. In large-scale population surveys the proportionally small number of TGNC respondents still limits the scope of statistical analysis, which can present barriers to publishing findings. However, despite these limitations, large-scale surveys offer the opportunity to compare the experiences of TGNC respondents with members of the 'general population'. This is what the 2014 YLT survey has to offer in relation to understand the educational experiences of TGNC youth in NI.

We report the findings of the 2014 YLT survey (ARK, 2015). YLT is an annual attitude survey of 16-year olds undertaken in NI. The random sample for the YLT survey is drawn from the Child Benefit Register. YLT is a postal survey with online and phone options. In 2014, 1,939 respondents completed the YLT survey. For the first time, respondents were given the option to self-identify as male, female, other, male-to-female transgender, or female-to-male transgender. Ten respondents in the sample identified as gender-non conforming - five said they were transgender, and another five said they were something other than male or female, but not transgender. For analytical purposes, we group these respondents here as TGNC. This relatively small number offers little scope for detailed statistical analysis of experiences within the group of TGNC respondents, but does enable binary analyses between TGNC respondents and other respondents. For analytical purposes we compare them to cis-hetero female/male respondents (i.e. those who identify as female/male and opposite-sex attracted) and non-heterosexual (i.e. those who identified as female/male and same-sex attracted). Survey data thus provides an important baseline of the number of 16 year olds living in NI who identify as TGNC as well as their experiences of homophobic and transphobic name calling in educational settings.

The 2014 YLT contains questions, also for the first time, on transphobic name calling and insults. At the design stage, detailed negotiations took place with the funder, advocacy organisations, and academic experts regarding the wording of the questions addressing 
transphobia. Strong differences in opinion emerged around the issue of whether or not to provide examples of transphobic terms in the question wording. On the one hand, some academics thought examples would help respondents recognise transphobic language and therefore aid reliable reporting. On the other hand, some representatives of TGNC advocacy organisations felt examples of abusive language could introduce young people to derogatory terms that they could use in the future. The funder followed the advice of the latter. The final version of the questions on transphobic insults included the words 'tranny' and 'transgender' as examples. This ignored the warning of one advisor who suggested 'a transphobic insult would rarely use the term "transgender", and the advice of academics who suggested that some young people would not recognise certain terms, such as 'she-male', 'he-she', 'fag', 'queer', etc. as having transphobic connotations. Due to the wording of the question, therefore, there is a possibility that the level of transphobic name calling is underreported.

In recognition of the methodological limitations of: a) the small proportion of TGNC respondents in the YLT survey, and b) the possibility of underreporting, we conducted semistructured interviews with TGNC youth to obtain subjective accounts of educational experiences. Recruitment procedures suggested by Elze (2009), including attending youth groups, snowballing, and referrals through adolescent service providers were utilised. These approaches, however, were only viable due to first author's history of engagement with NI's TGNC community. Researcher legitimacy was thus an important factor in making qualitative research possible on this sensitive topic (see Browne \& McBride 2015). Eight young people, who participated in a youth group for TGNC youth, initially agreed to be interviewed. However, of these, only three made themselves available for interview. The five young people who chose not to be interviewed had all experienced high levels of harassment and abuse at home and/or at school, which may have contributed to their decision to withdraw their participation. Another two young people were accessed through snowballing. In total, 
five young people were interviewed. Of these three identified as male and two who identified as female. Their ages ranged from 12 to 23. Interviews were audio recorded and anonymised on transcription. Once transcribed interview data was thematically coded and analysed for emergent themes. Due to the relatively small number of qualitative interviews conducted we do not draw firm conclusions in our analysis, but outline preliminary findings that require further investigation.

Finally, it is important to note that both authors identify as cisgender and heterosexual. Researcher positionality is extremely important when it comes to conducting research on historically marginalised groups (see McBride, 2016). Our status as 'gender conformist' can be viewed in numerous ways. On the one hand, it affords us critical distance from what is an emotive issue. On the other hand, there is risk of unintentionally reproducing unhelpful stereotypes and misconceptions. In light of this, we have approached this research with the question of how it might benefit TGNC youth (Rachlin, 2009). With this in mind the researchers set themselves the modest goal of aiming to produce knowledge that will contribute to the development of counter-heteronormative strategies and practices in educational settings.

\section{Results}

\section{Survey findings}

Demographically, TGNC respondents reflected the wider population dynamics of NI, as eight of the ten YLT respondents identified as White, and local diversity in terms of national identity (British, Irish, Northern Irish), financial background (high-, medium-, lowincome), location of home (city, town, rural), the type of school they attended (grammar, secondary, 'special needs') and the religious mix of their schools (Protestant, Catholic, 
integrated/mixed) was represented. Within this diversity though, three important commonalities emerged.

First, only $40 \%$ four out of the ten TGNC respondents had a religious affiliation compared to the YLT average of $72 \%$. This suggests a higher level of religious disengagement among TGNC youth. Second, $70 \%$ seven out of ten ef TGNC respondents identified as sexually attracted to same-sex people. This suggests a considerable overlap between TGNC and non-heterosexual identification in this age group. Finally, $50 \%$ half of the TGNC respondents identified as having a long-term illness or disability compared to the survey average of ten percent. The YLT survey does not capture details of disability or longterm illness, so it is not clear whether respondents considered their gender identity to be in any way associated with this.

YLT respondents were asked whether they themselves or their class mates had been insulted or called names using derogatory homophobic terms. Less than half of respondents who completed the YLT survey (46\%) said they had never experienced homophobic namecalling or insults by other pupils. Over half of all respondents reported that they were at the receiving end of homophobic name calling at various degrees ranging from 'rarely' to 'often' (almost every day). The gender difference here is significant with 58\% of cis-hetero identified females, $29 \%$ of cis-hetero males, but only $22 \%$ TGNC respondents saying they were never called homophobic names by their classmates. TGNC respondents were also more likely to be victims of homophobic name-calling than non-heterosexual respondents $(30 \%$ saying they had never been called names). One in three TGNC (33\%) respondents said this happened very often - i.e. almost daily - compared to $16 \%$ of cis-hetero males and five percent of cis-hetero females. Cis-hetero males were also more likely than cis-hetero females to report that they themselves $(7 \%)$ or their classmates $(14 \%)$ were ever called 'gay' or 'queer' by a teacher (cis-hetero females: $4 \%$ and $9 \%$ respectively). This compared to four in 
ten (40\%) TGNC respondents who said they had been called homophobic names by their teachers. Again this figure was even higher than among non-heterosexual respondents (18\%).

In contrast to homophobic experiences, transphobic name-calling and insults were found to rarely occur in school. Nine in ten (89\%) of all 16-year olds had never personally been called transphobic names by other pupils. In comparison, five in ten TGNC respondents reported never being called transphobic names. Even more striking was the difference in terms of awareness of classmates being called transphobic names. Two thirds of cis-hetero males and cis-hetero females (68\%) said that this never happened, compared to just half of non-heterosexual respondents and just one in ten TGNC respondents. Almost all cis-hetero males and females (97\%) said they had never been called transphobic names by teachers, whereas only seven in ten TGNC respondents said this. TGNC respondents were also much more likely than cis-hetero males and females to say that teachers had used transphobic terms against classmates and that teachers were called transphobic names by pupils.

\section{Interview results}

\section{Gender identity development}

Each interviewee described becoming self-aware that their gender identity did not match the social expectations of their assigned birth gender before the age of ten; with four interviewees stating this occurred between the ages of three and five. This self-awareness was typically associated with non-stereotypical desires, such as to dress and/or play with toys associated with the 'opposite sex'. Each interviewee reported a large gap between developing this self-awareness and living authentically in their preferred gender identity:

Sarah: "For me my life started in my late teens and twenties, up until now it has been a process it hasn't really been a life." 
This inability to live authentically and fully embody their subjective gender identity, was intimately connected to access to knowledge. For each interviewee representations of TGNC identities in offline and online media played a pivotal role in their own gender identity development:

Johnathan: "I didn't realise that female-to-male actually existed until I watched a film when I was 21 about a female-to-male person and I realised they exist and you could do something to live your life the way you wanted because before that I just thought oh my god I'm stuck and can't do anything."

Nicola: "I didn't have the internet until I was 16 but I knew from when I was 9. Things in the media like Dana [International performing at the 1998 Eurovision Song Contest], Nadia [a transgender identified contestant in a 2004 reality TV show] and [There's Something About] Miriam [a 2003 reality TV show about a male-to-female trans person] helped things to click into place before I could 'google it' and find out."

This delay between self-awareness and access to relevant knowledge lead some interviewees to experience confusion and conflate their gender identity and sexual orientation:

Mark: "I came out as a lesbian at 13 because I was just feeling weird and thought that will do for now. At 15/16 I came to realise that I wasn't a lesbian, but I didn't know how to phrase it [being TGNC]".

Johnathan: "Some people thought I was lesbian because at one point I had a girlfriend. The people in the school didn't understand that I was a guy they just thought I was a lesbian."

Lack of knowledge thus not only constrained interviewees' self-understanding and capacity to articulate their gender identity, it also shaped how other people viewed them. 


\section{Heteronormativity in educational environments}

All of the interviewees described negative schooling experiences due to heteronormative policies and practices. This is evident in the experiences of the two interviewees who attended 'single sex' schools:

Nicola: "My first three years [at secondary school were] single sex on the same ground as the female school. There were two communities [of boys]: your 'hoods', i.e. smoking dope and all that there, and the likes of going to band parades. If you were in-between or different you were outcasted."

Jonathan: "Being at an all-girls school was just so difficult. I had to wear a stupid girl's skirt and it was just horrible. I just wanted to be a guy and I couldn't understand why there were millions of girls."

Like Jonathan, interviewees who attended co-educational schools also had to negotiate heteronormative uniform policies:

Mark: "During my A-Levels I was pain in the ass. I was pushing the uniform rules and cutting my hair shorter and shorter. Wearing a girl's uniform was like going to school in drag every day in the worst possible way. I just constantly felt this wasn't the right thing for me. I just never felt comfortable in it at all. It didn't even look right on me. Outside school I had a masculine presentation. People thought I was a trans woman [male-to-female] who didn’t pass in the school uniform. I was going into the girls' toilets, in a girl's uniform, and getting asked if I was in the right bathroom."

Unlike Mark, whose school uniform became a site of subversive resistance, Sarah, who also attended a co-educational school, 'chose' to suppress her gender identity while at school: 
Sarah: "All the way through high school I had to hide who I was. I really just thought "just get through this just stay at the back of the class, don't look at anybody, don't make eye contact with anybody, just get the hell through this and then you can do whatever the hell you want after school."”

Sarah's fear of reprisal was not paranoia; four interviewees who began living in their preferred gender identity, either part-time or full-time, while still at school reported experiencing both homophobia and transphobia:

Jack: "There was some bullying at the start of the year. No one really said anything to me it was mainly someone else who would talk about me behind my back. Later in the year he wanted me to fight him, but that never happened."

Mark: 'I was getting bullied, getting 'tranny' and 'queer' shouted at me. Younger students were shouting abuse. It was consistent but I felt that it wasn't enough to go to a teacher about it or that they wouldn't believe me. It was mostly verbal. Very low-level, but it was constant. It happened so often, I didn't know what would happen when I went into corridor."

Sarah: "Secondary school was like having the rug pulled from under you. I was being treated like shit. It toughened me up, but the school didn't do anything despite knowledge of the bullying. There is a lot of homophobia with the teachers, they used the word 'fag' and 'queer' regularly."

Three interviewees discussed how their school curriculum and the attitudes of teachers were influenced by conservative Christian values:

Johnathan: "In my school we had religious education and in religious education I got the feeling that it's not okay to be gay and it's not okay to be lesbian and that was it. Trans people we weren't told anything about them, didn't know they existed. It would have been useful [to have information] because I actually spent a lot of sixth form hiding in my room 
because I wasn't happy what-so-ever. I would have understood why I felt depressed. I probably would have been much happier. Really need more information when you're younger."

Mark: "There's an [NGO] that offer LGBT workshops to teachers, [the NGO] said we have gone to your school but they have refused to take up the training. [My school] had a Christian ethos, although it didn't feel stiflingly religious. We would always have RE lessons and it got to the point where I would stand my ground and say look 'according to your religion I am an abomination so we are never going to get on here. You're not going to get through to me. They didn't like me after that."

Sarah: "For me I was the only person I knew [who was TGNC], I never met anyone like me so it was really difficult to understand what I was to do. It was really weird at times being the only person and nothing known much about it. [During a tutor group a preacher said gay people go to hell.] For me at that time it was so traumatising. That's a moment I'll remember for the rest of my life. I felt like a Jew in Nazi Germany. I had read a book and related to the situation."

For these three interviewees, conservative Christian values negatively impacted their educational experiences by erasing TGNC identities and stigmatising non-heterosexuality.

\section{Counter-heteronormative practices in educational environments}

Only one interviewee described a positive schooling experience. Following a terrible experience in primary school, in which he was rendered nameless by teachers who refused to call him by his preferred name or recognise his self-designated gender, Jack recounted how his time in secondary school was completely different:

Jack: "My mum told the principle [that I was being bullied] and they handled it as though I hadn't told them. They spoke to him [the bully] saying they had heard rumours around school 
about a fight and therefore he wouldn't think it was me and then it [the bullying] stopped. All the teachers are fine. I wear a boy's uniform and I use the boys' toilets and just get changed separately really. I am able to talk to my form tutor if I have any problems."

To better understand Jack's experience, one of his parents was interviewed: Anthony: "Jack has moved to secondary school. There he is being treated perfectly well by the headmaster and the teachers there. There have been a couple of minor bullying issues, but they have been dealt with. They are very open to be spoken to. We had a number of meetings before he started attending school and now I have a meeting with them at least once a term. I meet with the headmaster, the deputy head, a representative from the education board, and also a member from the [Children and Adolescent Mental Health Services] CAMHS team. So the CAMHS team and school link up and talk to each other. On a school level they do all they can to accommodate him. However, they said in the last meeting that the reason they were so good was because we have been through a court process and the court ordered that Jack be treated as a boy. That sounded ambiguous to me. What is the policy for someone who doesn't have a legal backing? It seemed to suggest that it was only because of the court that Jack is where he is. But that is the only negative I would say. They do very well by him."

Jack's experience suggest that proactive engagement can pre-empt some of the difficulties that arise when a young person who identifies as TGNC seeks to attend school in their authentic gender identity. It also suggests that ongoing dialogue between families, educators and other service providers can enable positive responses to unforeseen challenges.

\section{Discussion}

Findings from the YLT survey have provided a baseline of the relatively small number of 16 year olds living in NI who identify as TGNC. They also revealed the diverse demographics of this particular group of young people. However, across this diversity three tentative commonalities emerged in relation to religious disengagement, identification as 
non-heterosexual and as living with a long-term illness or disability. Although these identified commonalities require further investigation, these findings suggest that the identity of TGNC youth in NI is made up of multiple, intersecting social categorisations that go beyond gender identity. This may expose some TGNC in NI to overlapping and interdependent systems of discrimination and victimisation. This is reflected in the baseline findings that revealed TGNC respondents are more likely to experience both homophobic and transphobic abuse than either cis-hetero or non-heterosexual respondents. They were also likely to experience such abuse more frequently and have a heightened awareness of homophobic and transphobic insults being directed at classmates or teachers than others.

Qualitative data showed how experiences of TGNC youth's experiences of homophobia and transphobia are connected to the heteronormative structures, ethos, curriculum and policies of some schools in NI. Single-sex arrangements and gender normative uniform and haircut policies for example were found to impose gender binary stereotypes on TGNC youth. This leaves them with the 'option' of going to school every day in drag, as one interviewee put it, or breaking school rules, which in turn makes them vulnerable to informal (e.g. name calling) and formal (e.g. detention) sanctions. Interviewees who transgressed uniform and/or hair policies invariably experienced homophobic and transphobic abuse from pupils and teachers either infrequently or on an almost daily basis. All schools in NI are expected to operate effective anti-bullying policies, which prevent name-calling and bullying from taking place in school. However, this research found that interviewees were often unwilling to report experiences of homophobia and transphobia due to the religious ethos of their school. This is in line with the finding that interviewees who attended schools with a conservative Christian ethos reported that knowledge regarding TGNC identities was actively suppressed and non-heterosexual identities were discussed in a defamatory way. Such erasure and stigmatisation had a profound emotional impact on 
interviewees and for some rendered a life beyond the narrow confines of their assigned birth gender unimaginable. This suggests that despite NI's strong equality legislation, some TGNC youth are not treated equally in educational environments due to the overbearing nature of conservative Christian values, which silences open and positive discussion of gender variance and non-heterosexuality.

Taken together survey and qualitative findings suggests that there is a need to develop a broad range of counter-heteronormative interventions within NI's education system to overcome the challenges that TGNC youth experience. First, there is a need to develop, and sustain, pedagogical interventions that increase TGNC youth's social connectedness and enhance their resilience by equipping them with strategies to negotiate the heteronormative world they inhabit (see Barry \& Goodman, 2016). Second, schools should make a greater effort to provide parents and families of TGNC youth with information, education and access to peer and professional support (see Riley, Clemson, Sitharthan, \& Diamond, 2013). Third, school curriculums need to integrate comprehensive understandings of gender identity and sexuality (see Boskey, 2014) and educators must be provided with the adequate skills and resources to communicate this knowledge effectively (see Case \& Meier, 2012). Fourth, there is a need to draw on past experiences, such as Jack's detailed above, to develop a model for how schools can comprehensively support TGNC pupils (see Luecke, 2011). Such a model should be pre-emptive, based on sustained dialogue between key actors and grounded in the principles of acceptance, support, freedom of identity expression, validation and recognition (see Ehrensaft, 2014; Riley et al., 2013). It will also require the creation of safe spaces for TGNC youth, such as toilet and changing facilities, and require reconsideration of uniform and haircut policies. Fifth, in light of the high level of homophobic and transphobic abuse TGNC youth living in NI experience, there is a need to equip school counsellors, social workers, medical and mental health staff with the appropriate knowledge and skills to address 
TGNC youth's needs (see Clements-Nolle \& Marx, 2008). Finally, our findings suggest that TGNC youth in NI have complex identities and that professionals working with them will need to adopt a 'multidimensional' approach, which explores how different aspects of their identity interact. In particular, an effort needs to be made to neither confuse nor conflate issues of gender identity with sexuality, but to recognise that TGNC youth's gender identity and sexual orientation are likely to be fluid and evolve over time. This indicates that a onesize-fits-all professional approach or educational model will neither be appropriate nor effective. Rather general guidelines are required that can be applied in an idiosyncratic manner. 


\section{References}

\section{References}

Ansara, Y. G., \& Hegarty, P. (2012). Cisgenderism in psychology: pathologising and misgendering children from 1999 to 2008. Psychology and Sexuality, 3, 137-160.

ARK. (2015). Young Life and Times Survey, 2014 [computer file]. ARK www.ark.ac.uk/ylt [distributor].

Bantjes, J., \& Nieuwoudt, J. (2014). Masculinity and mayhem: The performance of gender in a South African boys' school. Men and Masculinities, 17, 376-395.

Barry, A. A., \& Goodman, R. (2016). The Impact of Social Connectedness and Internalized Transphobic Stigma on Self-Esteem among Transgender and Gender Non-conforming Adults, Journal of Homosexuality, [Accessed online 11 September 2016]

Boskey, E. R. (2014). Understanding Transgender Identity Development in Childhood and Adolescence, American Journal of Sexuality Education, 9, 4, 445-463.

Browne, B. C., \& McBride, R. (2015). Politically sensitive encounters: Ethnography, access and the benefits of "hanging out." Qualitative Sociology Review, 10, 35-48.

Burgess, C. (1999). Internal and External Stress Factors Associated with the Identity Development of Transgendered Youth, Journal of Homosexuality, 10, 3-4, 35-47.

Case, K. A. \& Meier, C. (2014). Developing Allies to Transgender and GenderNonconforming Youth: Training for Counselors and Educators, 11, 1, 62-82.

Clements-Nolle, K., Marx, R., \& Katz, M. (2006). Attempted Suicide Among Transgender Persons: The Influence of Gender-Based Discrimination and Victimization, Journal of Homosexuality, 51, 3, 53-69. 
Connell, R. (1989). Cool guys, swots and wimps: The inter-play of masculinity and education. Oxford Review of Education, 15, 291-303.

Conrad, K. (1999). Women troubles, queer troubles: gender, sexuality, and the politics of selfhood in the construction of the Northern Irish state, In: Marilyn Cohen and Nancy J. Curtin (eds.) Reclaiming Gender: Transgressive Identities in Modern Ireland, New York: St Martin's Press

DE. (2015). School enrolments: School level data. Bangor, Northern Ireland: Department of Education for Northern Ireland.

Ehrensaft, D. (2014). Found in Transition: Our Littlest Transgender People, Contemporary Psychoanalysis, 50, 4, 571-592.

Elze, E. D. (2009). Strategies for recruiting and protecting gay, lesbian, bisexual, and transgender youth in research process. In W. Meezan and J. I. Martin (Eds.), Handbook of research with lesbian, gay, bisexual, and transgender population. London, England: Routledge.

European Union Agency for Fundamental Rights (FRA) (2014). Being Trans in the European Union. Comparative analysis of EU LGBT survey data. Luxembourg: Publications Office of the European Union. Available online at: http://fra.europa.eu/sites/default/files/fra-2014-being-trans-eu-comparative-0_en.pdf [Accessed 6 October 2016]

Grossman, A. H. \& D'augelli, A. R. (2006). Transgender Youth: Invisible and Vulnerable, Journal of Homosexuality, 51, 1, 111-128.

Hayes, B. C. (1995). The Impact of Religious Identification on Political Attitudes: An International Comparison. Sociology of Religion, 56, 2, 177-194. 
Hayes, B. C., and Nagle, J. (2015). Ethnonationalism and attitudes towards gay and lesbian rights in Northern Ireland. Nations and Nationalism, 22, 1-22.

Haywood, C., \& Mac an Ghail, M. (1996). Schooling masculinities. In M. Mac An Ghaill (Ed.), Understanding Masculinties. Philadelphia, PA: Open University Press.

Hearn, J. (2007). The problems boys and men create, the problems boys and men experience. In T. Sheferm, K. Ratele, A. Strebel, N. Shabalala \& R. Buikema (Eds.) From boys to men: Social constructions of masculinity in contemporary society. Cape Town, South Africa: UCT.

Herek, G. (2004). Beyond "homophobia": thinking about sexual prejudice and stigma in the twenty-first century. Sexuality research and social policy, 1, 6-24.

Inglis, T. (1987). Moral Monopoly: the Catholic Church in modern Irish society. Dublin: Gill and MacMillan.

Ingraham, C. (1994). The Heterosexual Imaginary: Feminist Sociology and Theories of Gender, Sociological Theory, 12, 2, 203-219.

Irwin, J. (2002). Discrimination Against Gay Men, Lesbians, and Transgender People Working in Education, Journal of Gay \& Lesbian Social Services, 2002, 2, 65-77.

Jauk, D. (2013). Gender violence revisited: Lessons from violent victimization of transgender identified individuals. Sexualities, 16, 7, 807-825.

Kane, E. (2006). “Mo way my boys are going to be like that!” Parents' responses to children's gender nonconformity. Gender \& Society, 20, 149-176.

Kitchin, R. \& Lysaght, K. (2004). Sexual citizenship in Belfast, Northern Ireland, Gender, Place \& Culture, 11,1, 83-103. 
Lombardi, E. L., Wilchins, R. A., Priesing Esq., D., \& Malouf, D. (2002). Gender Violence: Transgender Experiences with Violence and Discrimination, Journal of Homosexuality, 42, 1, 89-101.

Linville, D. (2011). More than Bodies: protecting the health and safety of LGBTQ youth. Policy Futures in Education, 9, 3, 416-30.

Livingstone, D., Keane, M. \& Boal, F. (1998). Space for religion: a Belfast case study, Political Geography, 17, 145-170.

Luecke, J. C. (2011) Working with Transgender Children and Their Classmates in PreAdolescence: Just Be Supportive, 8, 2, 116-156.

McBride, R. (2011). Healthcare issues for transgender people living in Northern Ireland. Belfast, Northern Ireland: Institute for Conflict Research.

McBride, R. (2013). Grasping the nettle: The experiences of gender variant children and transgender youth living in Northern Ireland. Belfast, Northern Ireland: OFMdFM.

McBride, R. (2016). Researcher reflexivity in the age of neoliberal criminal justice policy and practice: towards hope, solidarity and re-humanism. In S. Armstrong, J. Blaustein \& A. Henry (Eds), Reflexivity and Criminal Justice: Intersections of Policy, Practice and Research. Basingstoke, England: Palgrave Macmillan.

McBride, R. \& Hansson, U. (2010). The luck of the draw: A report on the experiences of trans individuals reporting hate incidents in Northern Ireland. Belfast, Northern Ireland: OFMdFM.

Mitchell, M. C. (2006). Religion, identity and politics in Northern Ireland: boundaries of belonging and belief. Aldershot: Ashgate. 
Mitchell, M. \& Howarth, C. (2009) Trans Research Review. Manchester: Equality and Human Rights Commission.

Moi, T. (2005). Sex, Gender, and the Body. Oxford, England: Oxford University Press.

Nielsen, J. M., Walden, G., \& Kunkel, C. A. (2000) Gendered heteronormativity: Empirical illustrations in everyday life, Sociological Quarterly, 41, 2, 283-296.

Rachlin, K. (2009). The Questions We Ask: Conducting Socially Conscious Research with Transgender Individuals. In W. Meezan \& J. I. Martin (Eds.), Handbook of research with lesbian, gay, bisexual, and transgender population. New York, NYC \& London, England: Routledge.

Riley, E. A., Clemson, L., Sitharthan, G., \& Diamond, M. (2013) Surviving a Gender-Variant Childhood: The Views of Transgender Adults on the Needs of Gender-Variant Children and Their Parents, Journal of Sex \& Marital Therapy, 39, 3, 241-263.

Roen, K. (2016) The Body as a Site of Gender-Related Distress: Ethical Considerations for Gender Variant Youth in Clinical Settings, Journal of Homosexuality, 63, 3, 306-22.

Rofes, E. (2000). Bound and gagged: Sexual silences, gender conformity and the gay male teacher. Sexualities, 3, 439-462.

Rolston, B., Schubotz, D., and Simpson, A. (2005). Sex education in Northern Ireland schools: a critical evaluation. Sex Education 5, 217-234.

Saltmarsh, S. (2007). Cultural complicities: elitism, heteronormativity and violence in the education marketplace. International Journal of Qualitative Studies in Education, 20, $335-354$. 
Sigall, B. A. \& Pabst, M. S. (2005). Gender literacy: enhancing female self-concept and contributing to the prevention of body dissatisfaction and eating disorders. Social Science Information, 44, 85-111.

Toomey, R. B., McGuire, J. K., \& Russell, S. T. (2012). Heteronormativity, school climates, and perceived safety for gender nonconforming peers. Journal of Adolescence, 35, 187-96.

Yep, G. A. (2002). From homophobia and heterosexism to heteronormativity. Journal of Lesbian Studies, 6:3-4, 163-176.

Yep, G. A. (2003) The Violence of Heteronormativity in Communication Studies: Notes on Injury, Healing, and Queer World-Making, Journal of Homosexuality, 45, 2-4, 11-59. 